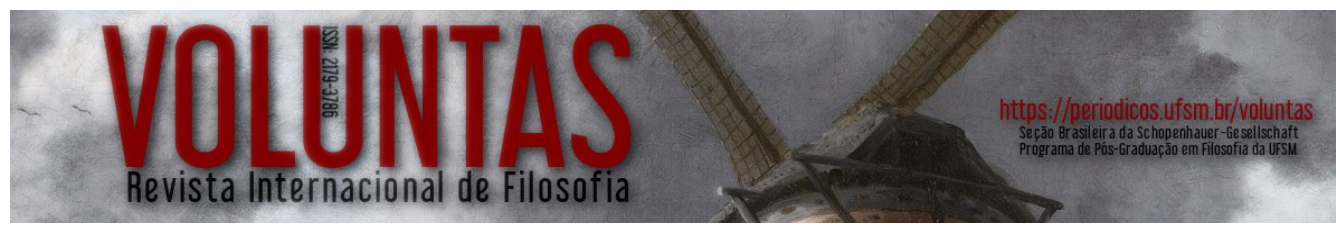

ISSN: 2179-3786 DOI: 10.5902/2179378633565

\title{
Pessimismo e sabedoria em Schopenhauer
}

Pessimism and wisdom in Schopenhauer

\author{
Aguinaldo Pavão \\ Professor do Departamento de Filosofia e do Programa de Pós-Graduação \\ em Filosofia da Universidade Estadual de Londrina (UEL) \\ E-mail: aguinaldo.pavao@hotmail.com
}

\begin{abstract}
Resumo: O artigo explora a alegação de Schopenhauer segundo a qual "toda a nossa existência é algo que seria melhor se não fosse, e que a suprema sabedoria [die größte Weisheit] consiste em negála e rejeitá-la”. Após o exame dessa tese, tento mostrar suas possíveis fragilidades. Embora nesse texto eu teça uma breve consideração sobre os Aforismos para a sabedoria de vida, dado que meu objetivo é a discussão sobre a suprema sabedoria e não sobre o sentido imanente de uma sabedoria de vida, deixo de lado a análise e discussão da eudemonologia exposta nos Parerga em benefício de uma mirada nos temas do pessimismo e da negação da vontade, claramente solidários com a ideia da suprema sabedoria apregoada por Schopenhauer na passagem acima citada. Faço isso porque não quero, pelo menos aqui, correr o risco de me desviar do ponto de vista superior, éticometafísico, da filosofia de Schopenhauer.
\end{abstract}

Palavras-chave: Sabedoria; Pessimismo; Existência; Ascese.

Abstract: The article analyzes Schopenhauer's thesis that "our whole existence is something that would be better if it were not, and that the supreme wisdom [die größte Weisheit] consists in denying it and rejecting it". After examining this thesis, I try to show its possible defects. Although in this text I briefly consider the Aphorisms on the wisdom of life, since my purpose is the discussion of the supreme wisdom and not the immanent sense of a wisdom of life, I leave aside the analysis and discussion of exposed eudemonology in Parerga for the sake of a look at the themes of pessimism and denial of will, clearly connected with the idea of the supreme wisdom defended by Schopenhauer in the passage quoted above. I do so because I do not want, at least here, take the risk to abandon the higher ethicalmetaphysical point of view of Schopenhauer's philosophy.

Keywords: Wisdom; Pessimism; Existence; Ascese.

$\mathrm{P}$

retendo neste artigo explorar a alegação de Schopenhauer segundo a qual "toda a nossa existência é algo que seria melhor se não fosse, e que a suprema sabedoria [die größte Weisheit] consiste em negá-la e rejeitá-la"1. A fim de examinar essa tese, assumo como ponto de partida uma estipulação semântica mínima do que vem a ser sabedoria. Tentarei mostrar que a compreensão de Schopenhauer sobre sabedoria pode, ou deveria poder, ser reconduzia a essa estipulação semântica mínima que logo irei expor. A bem da verdade, penso que a estipulação semântica a ser proposta possui uma íntima afinidade com a visão de Schopenhauer sobre sabedoria no sentido estrito. $\mathrm{O}$ artigo também relaciona a visão

\footnotetext{
${ }^{1}$ SCHOPENHAUER, A. P I, Aforismos para a sabedoria de vida, p. 146.
} 
sobre a suprema sabedoria com os dois caminhos para ascese em Schopenhauer. $\mathrm{Na}$ sequência, faço algumas considerações básicas sobre o pessimismo schopenhaueriano. Por fim, com um propósito mais experimental, destaco o que poderiam ser considerados pontos frágeis no entendimento de Schopenhauer sobre a suprema sabedoria. Esclareço que, embora lateralmente teça algumas observações sobre a sabedoria mundana dos Aforismos para a sabedoria de vida, a análise e discussão dessa obra será deixada de lado. Acredito que, procedendo assim, não correrei o risco de me desviar do ponto de vista superior, ético-metafísico, da filosofia de Schopenhauer.

Pode-se afirmar que sabedoria é uma qualidade que envolve, ao menos, dois elementos que se interligam: a) um componente epistêmico ou teórico, ou seja, as pessoas sábias sabem, ou conhecem, ou entendem certas coisas consideradas muito importantes para a condução da vida, ou do sentido e valor da existência humana em geral $^{2}$. b) um componente prático: as ações das pessoas sábias (ou, se quisermos, o modo de viver das pessoas sábias), em grande medida, refletem o conhecimento cuja posse caracteriza pessoas sábias. Essas estipulações são bem gerais e cumprem a função apenas de delimitação genérica do campo semântico dentro do qual poderei me movimentar ${ }^{3}$.

Embora esteja tão-só estipulando significados básicos, estou ciente de que a afirmação de que a sabedoria implica a interligação de elementos epistêmicos e práticos - ou teóricos e práticos - carrega consigo problemas. Alguém poderia protestar arguindo que a sabedoria é apenas teórica. E esse alguém a protestar poderia ser justamente Schopenhauer. Com efeito, no \ 25 do Tomo I de O mundo, ele usa a palavra sabedoria [Weisheit] no sentido exclusivamente teórico.

A essência em si, em verdade, está presente no todo e indivisa em cada coisa da natureza, em cada ser vivo. Dessa forma, nada perdemos, caso nos detenhamos em alguma coisa particular. A verdadeira sabedoria [wahre Weishei卂 não é adquirida medindo-se o mundo ilimitado ou, o que seria mais pertinente, sobrevoando pessoalmente o espaço infinito, mas antes investigando qualquer coisa em particular, procurando conhecer e compreender perfeitamente a sua essência verdadeira ${ }^{4}$.

Também se pode encontrar uma interessante referência à sabedoria, num sentido essencialmente teórico, no $\int 110$ dos Parerga.

Se compararmos estes conceitos fundamentais orientais [sobre vícios e virtudes cardinais] profundamente concebidos da ética com as tão celebres

\footnotetext{
2 Por coisas importantes para a vida deve-se entender temas como o bem e o mal, o certo e o errado, a doença, a morte e os sofrimentos em geral, tanto físicos como anímicos. De modo mais contundente, a ponderação das coisas mais importantes na (e para a) vida envolve um posicionamento, nem sempre refletido, sobre o que Schopenhauer considera a grande questão (die große Frage), a saber, sobre querer ou não querer a vida (cf. SCHOPENHAUER, A. MVR I, $₫ 56$, p. 397).

3 Aqui sigo as pegadas de Ryan (cf. RYAN, S. Wisdom). Cabe advertir que Ryan não discute em momento algum Schopenhauer. $\mathrm{O}$ artigo teve certa utilidade para mim porque me ofereceu ingredientes de inspiração.

4 SCHOPENHAUER, A. MVR I, \ 25, p. 190-191. Essas declarações de Schopenhauer ocorrem no contexto argumentativo do livro II do tomo I de O Mundo em que ele pretende assinalar que a coisa em si não está espalhada na extensão infinita do cosmos. Isso seria um grave erro, pois estaríamos tentando pensar a coisa em si por meio de uma linguagem que apenas pode nos dizer algo sobre o fenômeno. Sublinho que, nesse artigo, me interessa a sua concepção de sabedoria quando esta alcança o domínio prático.
} 
e mil vezes reiteradas virtudes cardinais platônicas - justiça, bravura, moderação e sabedoria [Gerechtigkeit, Tapferkeit, Mäßigkeit und Weisheit] -, notaremos que sem um conceito condutor fundamental e nítido, elas foram escolhidas de maneira superficial e em parte mesmo manifestamente falsa. Virtudes devem ser propriedades da vontade: a sabedoria, porém pertence em primeiro lugar ao intelecto ${ }^{5}$.

Tendo a discordar dessa alegação de Schopenhauer. Acredito que a virtude da sabedoria deve envolver também um elemento volitivo a fim de que possamos preservar a ligação entre o elemento epistêmico ou teórico e o prático. Com efeito, uma vez perdida essa ligação, perderíamos simplesmente o chão para apoiarmos nossos pés no caminho da compreensão filosófica do conceito de sabedoria. Além disso, a ligação entre o teórico e o prático é chancelada pelo próprio Schopenhauer (os abonos serão oferecidos mais para a frente) e me parece ser a sua tese mais forte sobre sabedoria. E se estiver certa a tese de que sabedoria não é virtude moral - no fundo concordo com esse ponto ${ }^{6}$-, é verdade, segundo Schopenhauer, que sabedoria expressa algo profundamente moral. Como mostrarei, esse é o caso, ainda que de modos diferentes, do compassivo e do asceta, visto que ambos levam uma vida que pode ser dita em alguma medida sábia - no caso do asceta não "em alguma medida", mas sim supremamente sábia. Quer dizer, na virtude e na santidade se faz presente a sabedoria. Sendo assim, vale consignar que a sabedoria que aqui pretendo discutir é entendida como uma qualidade intelectual e moral.

$\mathrm{Na}$ verdade, posso oferecer algo mais valioso nessa possível contenda sobre se sabedoria seria apenas teórica. Tenho em mente uma passagem do capítulo intitulado Observações psicológicas do Tomo II dos Parerga. No \339 desse capítulo se lê:

Há conceitos que raramente estão presentes de forma clara e definida em alguma mente, antes, prorrogam sua existência unicamente por meio de seus nomes, que na realidade não designam mais que um lugar de tais conceitos, e sem os quais se perderiam por completo. Deste tipo é, por exemplo, o conceito de sabedoria [der Begriff der Weisheit]. Quão vago é em quase todas mentes. Vejam as explicações dos filósofos.

A sabedoria [Weisheit] parece-me designar uma perfeição não meramente teórica, mas também prática [Weisheit scheint mir nicht bloß theoretische, sondern auch praktische Vollkommenheit zu bezeichnen.] $]^{7}$. Eu a definiria como o pleno e correto conhecimento das coisas em conjunto e em geral, conhecimento que penetrou no homem tão plenamente que se manifesta também em sua conduta, ao dirigir sempre ao seu agir ${ }^{8}$.

Reconheço aqui - e acho que o leitor também facilmente reconhecerá - uma notável convergência, nos seus termos gerais, com a estipulação semântica que propus acima.

\footnotetext{
${ }^{5}$ SCHOPENHAUER, A. P II, \ 110, p. 41-42.

${ }^{6} \mathrm{Um}$ esclarecimento: concordo que a sabedoria não seja uma virtude moral. Isto é, concordo que rigorosamente ela não é uma qualidade do caráter como podem ser entendias as virtudes da justiça e da caridade. A sabedoria certamente tem um componente moral, mas não se reduz ao domínio moral. Espero deixar isso mais claro ao longo do texto.

7 Tradução de Pilar López de Santa María ligeiramente modificada.

8 SCHOPENHAUER, A. P II, $\$ 339$, p. 613.
} 
Antes de prosseguir e apresentar o conteúdo dos componentes práticos e teóricos da sabedoria em Schopenhauer, vale ressaltar que nesse texto estou comprometido com a hipótese de leitura segundo a qual a sabedoria, para o autor de O mundo como vontade e representação, no sentido mais forte do termo, é aquela que se encontra no modo ascético de viver, tal como descrito no livro IV de sua obra magna. Portanto, na minha opinião, para Schopenhauer há um único modo de alguém ser autenticamente sábio (ainda que não enunciada literalmente, essa é a tese de $O$ mundo, não a dos Aforismos, como explicarei) ${ }^{9}$.

É possível sustentar que Schopenhauer oferece duas teorias sobre sabedoria. Uma, como disse, a que se pode recolher de sua obra magna, $O$ mundo como vontade e representação - que é a que aqui me interessa. Outra, e talvez a mais comentada, a que encontramos no I tomo dos Parerga, no famoso texto Aforismos para a sabedoria de vida. Essas duas teorias não são, ao menos inicialmente, passíveis de conciliação. A primeira ensina a negação da vontade. A segunda esclarece e propõe algumas técnicas para vivermos de modo menos infeliz possível.

Até caberia uma terceira, ou uma teoria da sabedoria aliada à clarividência metafísica que pode conduzir à ascese. Essa seria não exatamente a sabedoria da ascese, nem a sabedoria para a vida dos Aforismos, sabedoria que é tomada "em sentido imanente" 10 , mas sim a sabedoria do homem moralmente superior, homem verdadeiramente bom, compassivo, que reconhece a sua verdadeira essência "imediatamente no outro". "De acordo com isso", diz Schopenhauer,

a sabedoria prática [praktische Weisheit], o agir reto e o bem agir coincidiriam exatamente no resultado com a doutrina mais profunda da sabedoria teórica de mais amplo alcance, e o filósofo prático, quer dizer, o justo, benfeitor e generoso, expressaria pela ação tão-só o mesmo conhecimento que o resultado da maior profundidade de pensamento e da mais difícil pesquisa dos filósofos teóricos. Todavia, a excelência moral está bem acima do que toda a sabedoria teórica, como a que é a sua obra incompleta e que atinge, pelo lento caminho da dedução, o alvo que a primeira alcança de um golpe. E a nobreza moral, mesmo se ainda lhe falta excelência intelectual, põe à luz, pelas suas ações, a mais alta sabedoria [die böchste Weishet] e envergonha o mais genial e o mais erudito, quando este mostra, pelo seu comportamento, que aquela grande verdade ficou alheia a seu coração ${ }^{11}$.

\footnotetext{
${ }^{9}$ Mas, registre-se, a afirmação textual que apoia e motiva os comentários que apresento nesse artigo encontramse, talvez por uma ironia filosófica, nos Aforismos, um livro que defende, num certo sentido, outra sabedoria (digo "outra" aqui para não antecipar um possível juízo de que ela não seria rigorosamente sabedoria).

10 Cf. SCHOPENHAUER, A. P I, Aforismos para a sabedoria de vida, p. 1.

${ }^{11}$ SCHOPENHAUER, A. M, p. 207. Em comentário a essa passagem de Sobre o fundamento da moral, Gardiner, com acerto, afirma: "um homem pode ter uma habilidade teórica completamente deficiente e, contudo, demonstrar ou revelar por meio de suas ações a mais profunda intuição e sabedoria, sem que seja capaz de articulá-las ou formulá-las conceitualmente. Desse ponto de vista se pode dizer que a significação de suas ações é obscura para ele. E ocorre o mesmo com a concepção do que faz com o que o move a fazê-lo; o ponto fundamental aqui está mais próximo do 'sentimento' do que de uma reflexão ou cálculo racional” (GARDINER, P. Schopenhauer, p. 274).
} 
Vale registrar que tal sabedoria, que chamarei aqui de sabedoria ética para distingui-la da suprema sabedoria, que é a que se pode chamar de sabedoria ascética ${ }^{12}$, está, pois, também ligada ao conhecimento que suprime o princípio da individuação (voltarei a esse ponto) ${ }^{13}$.

Nesse momento julgo oportuno fazer algumas breves considerações sobre sabedoria nos Aforismos e sua diferença com a suprema sabedoria. Talvez todos os esforços de Schopenhauer para oferecer uma visão mais atrativa sobre o tema da sabedoria, em especial aqueles empreendidos nos Aforismos, não ofusquem sua tese filosófica principal de que a sabedoria não é propriamente um saber viver, mas um não querer mais viver, não querer mais afirmar a vontade, algo dito por ele mesmo no texto dedicado a uma sabedoria para a vida. Embora o aprofundamento dessa discussão não me interesse aqui, posso fazer algumas breves e pontuais considerações a esse respeito - as quais precisariam naturalmente de um melhor desenvolvimento, o que fica para outra oportunidade.

De acordo com a introdução aos Aforismos, e em perfeita consonância com o que já havia sido estabelecido em sua obra principal, Schopenhauer nega que a vida humana possa corresponder ao conceito de vida feliz ${ }^{14}$. Sendo assim, a possibilidade que Schopenhauer vislumbra para a abordagem do tema da "arte de conduzir a vida do modo mais agravável e feliz possível"15, isto é, do tema da sabedoria de vida, envolve um desvio total, como ele diz,

do ponto de vista superior, ético-metafísico, ao qual conduz a minha filosofia propriamente dita. Por conseguinte, toda a discussão aqui conduzida baseia-se, de certo modo, numa acomodação, já que permanece presa ao ponto de vista comum, empírico, cujo erro conserva. Logo, também o seu valor só pode ser condicional, pois até mesmo a palavra eudemonologia não passa de um eufemismo ${ }^{16}$.

Tendo isso em mente, não devemos nos surpreender que mesmo dentro desse livro, no capítulo V, intitulado "Parênteses [exortações] e máximas", Schopenhauer declare o que entende por uma "suprema sabedoria". Cito novamente, e agora de forma mais ampla, a importante passagem que motiva esse artigo. Nela se lê:

Quem, entretanto, estiver imbuído dos ensinamentos da minha filosofia e, por conseguinte, souber que toda a nossa existência é algo que seria melhor se não fosse, e que a suprema sabedoria [die größte Weisheit] consiste em negá-la e rejeitá-la, não nutrirá grandes esperanças por coisa alguma ou

\footnotetext{
12 Essa nomenclatura não tem importância para o meu ponto. Ao referir-me a uma sabedoria ética e a outra ascética quero apenas fixar a diferença entre uma sabedoria vivida pelo homem virtuoso daquela vivida pelo asceta. O caminho da virtude para ascese não é um caminho necessário. Quando tratar mais à frente dos caminhos para a negação isso ficará mais evidente.

13 SCHOPENHAUER, A. MVR I, \ 68, p. 503: “todo amor puro e verdadeiro, sim, até mesmo toda justiça livre já resultam da visão através do principii individuationis, a qual, caso entre em cena com sua plena força, produz a completa salvação e redenção".

${ }^{14}$ Cf. SCHOPENHAUER, A. P I, Aforismos para a sabedoria de vida, p. 1.

15 Ibidem.

${ }^{16}$ Idem, p. 1-2.
} 
situação; a nada no mundo aspirará com ardor nem entoará grandes lamentações diante de um malogro ${ }^{17}$.

A partir dessa citação é possível afirmar que Schopenhauer pensa a sabedoria de vida dos Aforismos como uma sabedoria bastarda. Digo isso pensando num contraste entre o que os Aforismos procuram ensinar e a noção de "suprema sabedoria". Com efeito, a suprema sabedoria não nos levaria a sequer realizar qualquer esforço para vivermos bem, ou vivermos de modo menos infeliz possível. Deveríamos, se supremamente sábios fôssemos, nos conduzir com uma sabedoria de negação da vida. (Quero deixar claro que não uso a palavra "deveríamos" aqui no sentido de que seria necessário obedecer a prescrições. $\mathrm{Na}$ frase acima o "deveríamos" cumpre o propósito singelo de indicar o que está implicado na ideia de um viver sabiamente).

Gostaria de destacar agora o componente teórico que pode ser depreendido da passagem dos Aforismos citada. A referida suprema sabedoria depende de algo intelectual, de um conhecimento, convergindo, nesse ponto, com a visão comum de sabedoria, pois geralmente se pensa que o sábio dispõe de um certo conhecimento, de uma compreensão mais profunda do que realmente é importante na vida, que pressupõe, é verdade, uma reposta à chamada "grande questão" [die große Frage] - como lemos no \56 de $O$ mundo como vontade e representação -, isto é, à questão sobre querer ou não querer a vida ${ }^{18}$.

Para Schopenhauer, a luz do conhecimento abranda a violência da vontade, o que põe em relevo a importância do elemento teórico para a sua visão de sabedoria. E esse conhecimento é conhecimento que vê para além do princípio da individuação, para além da forma dos fenômenos.

Com isso, os até então poderosos motivos perdem o seu poder e, em vez deles, o conhecimento perfeito da essência do mundo [die vollkommene Erkenntni $\beta$ des Wesens der Welt], atuando como quietivo da Vontade, produz a resignação, a renúncia, não apenas da vida, mas de toda a Vontade de vida mesma ${ }^{19}$.

Eis aí o elemento epistêmico ou teórico a que me referi antes, o primeiro dos elementos que compõe a ideia básica de sabedoria aqui assumida, sendo o segundo o elemento prático - visto que esse conhecimento implica um modo de viver, pois mesmo que se trate de negação da vontade, enquanto perdurar o asceta, há vida, ainda que volitivamente aquietada.

Passemos ao componente prático da sabedoria. É significativo que Schopenhauer diga, na passagem acima citada dos Aforismos, que a suprema sabedoria consiste em negar a existência. Ora, esse "negar a existência" ressalta um elemento prático como consequência do entendimento do não valor da existência. A suprema sabedoria não é, assim, uma sabedoria meramente teórica. Em Schopenhauer não basta a intelecção de que a vida é sofrimento ${ }^{20}$ para que se viva de modo coerente

\footnotetext{
${ }^{17}$ Idem, p. 146.

${ }^{18}$ Cf. SCHOPENHAUER, A. MVR I, \56, p. 397.

19 Idem, \51, p. 333.

20 Talvez se possa admitir que se trate de algum esforço reflexivo para o filósofo, não para o sábio, visto que quem ingressa na vereda da ascese é beneficiário da graça e não rigorosamente de um esforço, de alguma
} 
com essa compreensão. É preciso mais. É preciso que essa reflexão se torne uma "convicção viva" (lebendigen Überæẹngung) ${ }^{21}$. Não pode ser um puro saber abstrato ${ }^{22}$. Num certo sentido, sempre que se pensa num homem sábio, imagina-se um ser que não padece de akrasia (de incontinência, ou se quisermos de fraqueza da vontade). Ou seja, o seu saber sobre o que são as coisas importantes da vida não é inoperante, ou pelo menos se admite que ele é predominantemente enkrático (continente) em relação a esse saber profundo, ainda que a enkrateia nesse contexto não deva ser pensada em termos intelectualistas, isto é, amparada em um saber meramente abstrato.

Assumindo que a vida seja um negócio que não cobre os custos do investimento - uma tese obstinadamente defendida por Schopenhauer -, o sábio reconhece que "não podemos assinalar outro fim a nossa existência senão o de aprender que seria melhor que não existíssemos" 23 , haja vista que essa é, como se pode ler no Suplemento 48, "a mais importante de todas as verdades" [die wichtigste aller $W$ abrheiten] ${ }^{24}$. Porém, no fundo, não se trata apenas de uma aquiescência intelectual a essa verdade. Tratase de uma consequência também existencial: o sábio vive "a mais importante de todas as verdades".

Ademais, é importante reforçar que Schopenhauer não defende que essa sabedoria, a suprema sabedoria, deva nos envolver desiderativamente, isto é, ser apresentada como uma demanda prescritiva a nossas vidas ${ }^{25}$. De todo modo, é certo que para o elemento prático se fazer presente tem de ocorrer um envolvimento desiderativo, por isso afirmei antes que a compreensão do sentido e valor da existência não pode ser um "mero saber abstrato", mas uma "convicção viva" 26 . Ressalta-se assim, os dois elementos a que me referia sobre sentido básico de sabedoria, isto é, o componente epistêmico ou teórico (um saber sobre as coisas mais importantes para condução da vida, ou do sentido e valor da existência humana em geral) e o prático (ações coerentes com o que se sabe sobre as coisas mais importantes para a condução da vida). Num certo sentido, pode-se dizer que aí cabe um louvor prático-moral, ainda que não uma prescrição. Sobre o cabimento de um louvor prático-moral, Schopenhauer mesmo se refere expressamente à vida do asceta como uma "vida invejável" (beneidenswerthe Leben) ${ }^{27}$.

\footnotetext{
diligência deliberativa. Concedo, assim, provisoriamente que a compreensão de que a vida é sofrimento possa ser, para o filósofo, o resultado de uma profunda reflexão sobre o sentido da existência. Nesse sentido, tem alguma utilidade a indicação da diferença entre o filósofo e o santo (cf. SCHOPENHAUER, A, MVR I, \68, p. 486-487).

${ }^{21}$ SCHOPENHAUER, A. MVR I, $\int 57$, p. 406.

${ }^{22}$ Cf. Idem, $₫ 56$ e 57, pp. 400 e 406.

23 SCHOPENHAUER, A. MVR II, p. 722.

${ }^{24}$ Ibidem.

${ }^{25}$ De acordo com a visão de Schopenhauer, no campo da ética ou, se quisermos, mais amplamente no campo do significado moral das ações não cabe prescrições e o dever é um conceito cujo significado somente pode ser relativo. Tratei desse tema em: PAVÃO, A. Kant e Schopenhauer sobre a natureza da filosofia moral, p. 135-148.

${ }^{26}$ SCHOPENHAUER, A. MVR I, $\int 56$ e $\int 57$, pp. 400 e 406.

${ }^{27}$ Cf. Idem, \68, p. 486. Essa vida invejável, ao envolver desiderativamente o sujeito, acarreta os seguintes passos: $1^{\circ}$ ) "voluntária e completa castidade" (MVR I, \68, p. 483); $2^{\circ}$ ) "pobreza voluntária e intencional" (MVR I, \68, p. 484); $3^{\circ}$ ) aceitação da maldade, injuria, ignomínia e danos em geral sofridos trazidos do exterior. O asceta "paga o mal com o bem" (MVR I, $\int 68$, p. 485). Como um quarto passo ascético pode-se mencionar a mortificação de seu corpo (a objetidade da Vontade). "Assim, pratica o jejum, sim, pratica a castidade, a autopunição, o autoflagelo, a fim de, por constantes privações e sofrimentos, quebrar e mortificar cada vez
} 
Nessa altura, parece-me apropriado assinalar os dois caminhos possíveis para a negação da vontade em Schopenhauer ${ }^{28}$. O primeiro caminho, mais raro, é o que parece, à primeira vista, melhor se ajustar à ideia que venho defendo da importância do conhecimento para a sabedoria, isto é, com o primeiro elemento da estipulação semântica que assumi, de acordo com o qual a sabedoria implica um componente epistêmico ou teórico. Com efeito, no primeiro caminho, o conceito de sabedoria aqui exposto obtém, de fato, maior realce, haja vista que Schopenhauer mesmo afiança que já o homem bom é um sábio no sentido prático. E embora haja essa qualificação de prático ao homem sábio, sábio por ser bom, a afirmação de Schopenhauer deixa transparecer a ideia de que essa sabedoria mantém uma relação ou uma afinidade com a suprema sabedoria. A razão disso é que ela se refere a uma certa compreensão do mundo. Nessa compreensão um novo horizonte desponta, uma verdade profunda é captada, a verdade de que há uma identidade metafísica entre os seres, sendo todos fenômenos da vontade, vontade essa que é o "em-si" de todas as coisas. Reforçando, poderíamos dizer que esse seria o lado epistêmico ou teórico dessa sabedoria moral. O lado prático, seria, como fica fácil depreender, o próprio modo de agir do compassivo $^{29}$. Para que tenhamos a ideia desse primeiro caminho percorrido precisamos assumir que o compassivo transitaria de seu estágio virtuoso para o estágio ascético ou santo ${ }^{30}$.

Agora, temos de reconhecer a segunda via para a ascese. É possível, segundo Schopenhauer, atingir a negação da vontade não por um sofrimento meramente conhecido, mas também por um "sofrimento pessoalmente sentido" 31 . Essa é a via da maioria daqueles que ingressam na vereda da negação da vontade ${ }^{32}$. Nessa via não é o conhecimento do sofrimento, que permeia toda a vida, o produtor do efeito ascético. Aqui, é o próprio sofrimento experimentado que conduz à viragem e redenção da vontade. É a dor sentida de modo exaltado, os padecimentos dos maiores sofrimentos, os quais podem, inclusive, levar pessoas perversas à negação da vontade, a uma aceitação serena e até alegre da morte. A partir desse sofrimento pessoal é possível ver a afirmação da vontade como algo até mesmo repugnante ${ }^{33}$. Para Schopenhauer, nessa segunda via,

vemos o homem trazido às raias do desespero após haver sofrido todos os graus de uma aflição crescente sob os reveses mais violentos, subitamente retirar-se em si mesmo, reconhecer-se a si e ao mundo, mudar

\footnotetext{
mais a Vontade, que reconhece e abjura como a fonte de sofrimento da própria existência e do mundo" (MVR $\mathrm{I}, \int 68$, p. 485).

28 Sobre as duas vias de negação da vontade e o denominado deuteros plous, ver: SCHOPENHAUER. A. MVR I, \68, pp. 496-497. Cf. também: MVR II, p. 749; MVR II, p. 760 e P II, Suplementos à doutrina da afirmação e da negação da vontade de viver, $\int 170$, p. 182. Considerar também a própria sequência desse artigo.

${ }^{29}$ Esclareço que não tenho como objetivo nesse texto a análise e discussão do conceito de sabedoria moral em Schopenhauer. Apenas destaco aqui que, com respeito à primeira via para a negação da vontade, a sabedoria moral mantém relevante afinidade com a sabedoria ascética. Em suma, uma sabedoria apenas moral ainda não seria a suprema sabedoria.

${ }^{30}$ Uma transição (como já assinalei em outra nota) não necessária.

31 SCHOPENHAUER, A. MVR I, $\int 68$, p. 497.

${ }^{32} \mathrm{Na}$ verdade, esse é "o caminho dos pecadores", que somos todos nós (cf. SCHOPENHAUER, A. MVR II, p. 760).

${ }^{33}$ Cf. SCHOPENHAUER, A. MVR II, p. 756.
} 
todo o seu ser, elevar-se por sobre sua pessoa e todo sofrimento, como se fora purificado e santificado por este, em paz inabalável, em beatitude e sublimidade, livremente renunciando a tudo o que antes queria com a maior veemência, e receber alegremente a morte ${ }^{34}$.

Note-se que mesmo no segundo caminho há um ingrediente claramente teórico, embora talvez mais fugaz, ou com menos constância e estabilidade biográfica em comparação com aquele primeiro caminho baseado na intelecção do sofrimento de todo existir. Ainda que essa segunda via seja aberta pela experiência pessoal, ela requer, ou melhor produz, um modo diferente de ver as coisas, portanto uma diferente forma de conhecimento que também envolve a ultrapassagem do princípio da individuação, pois, como diz Schopenhauer:

no excesso de dor [revelou-se] o último mistério da vida, vale dizer, por mais que o padecimento e a maldade, o sofrimento e o ódio, o torturado e o torturador se mostrem diferentes segundo o conhecimento que segue o princípio de razão, em si mesmos são unos, fenômenos daquela Vontade de vida que objetiva seu conflito consigo mesma via principii individuationis $^{35}$.

Com o propósito de melhor compreender o repúdio de Schopenhauer da possibilidade de uma vida feliz e assim penetrar com mais profundidade no tema da sabedoria, é preciso apresentar em linhas gerais os termos do pessimismo schopenhaueriano (que pode ser entendido aqui como o ingrediente essencial do componente epistêmico ou teórico da sabedoria).

Com efeito, a sabedoria da negação da vontade e do reconhecimento de que melhor seria não existir tem como base uma compreensão pessimista do mundo e da existência. Para que se compreenda o que quero dizer com pessimismo de Schopenhauer, que poderia licitamente ser chamado de pessimismo metafísico ${ }^{36}$, é necessário considerar, inicialmente, que - como ensina o Mundo como vontade $e$ representação - a vontade é a essência de tudo que existe, ou se se preferir o "em-si de toda coisa [Ansich jedes Dinges]" 37. Ora, essa essência, ou "em-si" de toda coisa, é um esforço (Streben) que se encontra em todos os corpos, ${ }^{38}$ sendo, pois, o "núcleo e

\footnotetext{
34 SCHOPENHAUER, A. MVR I, \$ 68, p. 497.

35 Idem, p. 498-499. A esse respeito, julgo correta a seguinte interpretação sobre Schopenhauer. "A conversão do querer tem sempre como condição a conversão do intelecto. Que a libertação seja alcançada, na maioria das vezes, pela experiência direta, perturbadora, do sofrimento, não implica de maneira alguma que o querer-viver possa ser abolido antes de ser reconhecido como um erro. A salvação é uma gnose" (LEFRANC, J. Compreender Schopenhauer, p. 171). Na sequência imediata, Lefranc dá como abono uma passagem do $\ 172$ dos Parerga. A passagem é esta: "Minha visão de mundo [...] encara a própria existência como algo que melhor seria se não fosse, como uma espécie de extravio do qual o conhecimento deveria nos desviar" (SCHOPENHAUER, A. PP II, \172a, p. 185).

${ }^{36}$ Digo isso porque o pessimismo de Schopenhauer deita raízes numa cosmologia filosófica. Assim, a expressão "pessimismo metafisico" é deveras singela e é o único pessimismo consequente que reconheço em Schopenhauer.

${ }^{37}$ SCHOPENHAUER, A. MVR I, \56, p. 399.

38 Cf. por exemplo em: SCHOPENHAUER, A. MVR I, \56, p. 398. Ver também SCHOPENHAUER, A. MVR I, JS 19-21, pp. 160-169.
} 
essência de um mundo reconhecido como povoado de penúrias"39 e "ao qual nenhum fim alcançado põe um término" 40 . A vontade não atua com alguma finalidade; pelo contrário, ela é destituída de qualquer finalidade, podendo ser caracterizada como um "ímpeto cego e irresistível" 41 que nunca se satisfaz ${ }^{42}$. Uma vez que todo querer nasce de uma carência, o querer sempre é sofrimento. Ora, viver é querer. Logo, viver é sofrer. Assim, o estado de perpétuo sofrimento é o estado de todos os seres no mundo, todos submetidos ao domínio da vontade. Sujeito ao jugo da vontade, como não poderia ser diferente, o ser humano não pode ser feliz ${ }^{43}$.

Por conseguinte, à pergunta "o homem sábio é feliz?", a reposta de Schopenhauer tem de ser evidentemente negativa. O homem sábio não é feliz (gostaria de lembrar que estou levando em consideração apenas a suprema sabedoria da negação da vontade), visto que a felicidade é um estado que nenhum ser humano pode alcançar num mundo permeado de sofrimento. "Uma vida feliz é impossível" 44. Para Schopenhauer, "Tudo na vida nos ensina que a felicidade terrena está destinada a desvanecer-se ou a ser reconhecida como uma ilusão" 45 . Embora sendo a felicidade impossível, Schopenhauer vislumbra uma porta para a redenção, para a libertação do jugo da vontade. Essa saída é a negação da vontade, possível quando se obtém um conhecimento da essência do mundo, conhecimento que vê para além do Véu de Maia, da ilusão dos fenômenos ${ }^{46}$. Trata-se, como se viu, da ascese, da suprema sabedoria. (Não tem importância, para o desenvolvimento do argumento, a contemplação estética que proporciona uma fugaz libertação do jugo da vontade. Ademais, o gênio não se confunde com o sábio, visto que somente a figura desse último reclama algo moral $\left.{ }^{47}\right)$.

Tendo feito um exame dos ingredientes conceituais implicados na noção de suprema sabedoria, parece-me salutar tentar apresentar possíveis críticas à posição de Schopenhauer. Minha intenção nessa parte do artigo é expor desafetadamente algumas dúvidas que tenho sobre a validade da compreensão de Schopenhauer sobre a suprema sabedoria. A bem da verdade, olhando-as com mais rigor, elas se tornam

\footnotetext{
${ }^{39}$ SCHOPENHAUER, A. MVR I, \ 68, p. 482. "O mundo é bem o inferno e os homens são por um lado as almas atormentadas, por outro, os demônios” (SCHOPENHAUER, A. PP II \156, pp. 157-158).

40 SCHOPENHAUER, A. MVR I, S 56, p. 398.

${ }^{41}$ Idem, $\int 54$, p. 357.

42 Idem, \ 68, p. 503: “Até então [até "a completa negação a Vontade"] cada um não passa dessa Vontade, cujo fenômeno é uma existência efêmera, um esforço sempre nulo e continuamente malogrado, o mundo tal como exposto, cheio de sofrimento, ao qual todos pertencem irrevogavelmente de maneira igual".

43 Cf. Idem, \56, p. 399; e MVR II, p. 683. Nesse contexto, cabe a famosa passagem de $O$ mundo, \ 38. "Todo QUERER nasce de uma necessidade, portanto de uma carência, logo, de um sofrimento. A satisfação põe um fim ao sofrimento; todavia, contra cada desejo satisfeito permanecem pelo menos dez que não o são. Ademais, a nossa cobiça dura muito, as nossas exigências não conhecem limites; a satisfação, ao contrário, é breve e módica. Mesmo a satisfação final é apenas aparente: o desejo satisfeito logo dá lugar a um novo: aquele é um erro conhecido, este um erro ainda desconhecido. Objeto algum alcançado pelo querer pode fornecer uma satisfação duradoura, sem fim, mas ela se assemelha sempre apenas a uma esmola atirada ao mendigo, que torna sua vida menos miserável hoje, para prolongar seu tormento amanhã (SCHOPENHAUER, A. MVR I, \ 38, p. 266).

44 SCHOPENHAUER, A. PP II, \172, p. 185.

${ }^{45}$ SCHOPENHAUER, A. MVR II, p. 683.

46 "Uma reflexão madura leva ao resultado de que a uma existência como a nossa seria preferível o completo não ser" (SCHOPENHAUER, A. PP II \135, p. 118).

${ }^{47}$ Tendo isso em vista, não vejo como se possa concordar com a afirmação de que o sábio schopenhaueriano seria um esteta" (SCHIFFER, F. Filosofia sentimental, p. 64). Não só "esteta" aí me parece impreciso, como a eventual emenda de gênio no lugar de esteta resultaria num equívoco.
} 
secundárias em relação à defesa da interpretação, desenvolvia acima, que consistiu em advogar a favor da hipótese de que, para Schopenhauer, a sabedoria, entendida estritamente, é a sabedoria do pessimismo metafísico que reivindica não um viver menos infeliz, mas simplesmente o reconhecimento teórico e efetivo (prático, vivencial) de que o melhor seria negar e rejeitar a existência.

Pois bem, inicialmente, gostaria de levantar a questão sobre se a filosofia não deveria nos fornecer modelos mais humanos - ou, se quisermos atentar para a natureza não prescritiva da filosofia de acordo com Schopenhauer -, se a filosofia não deveria nos conduzir a elucidações sobre formas sábias de condução da vida que estejam mais de acordo com o modo comum de viver dos homens. Uma sabedoria possível apenas para agraciados por um saber não abstrato que permite ver além do Véu de Maia, ou seja, por seres favorecidos por um conhecimento que precisa ser ilustrado com recursos místico-religiosos como "efeito da graça" não representa uma ruminação filosófica excessivamente deslocada do saudável entendimento comum? Parece-me mais defensável uma compreensão de sabedoria que acolhe nossa existência terrena em seus próprios termos sem evasões da nossa natureza sensível, desejante. Com efeito, pode-se afirmar que a tese de que a ascese representa a "suprema sabedoria" [die größte Weisheit] implica evasão da vida. Ora, somente de modo muito penoso uma sabedoria como evasão da vida pode ser entendia como sabedoria. A aceitação das limitações da condição humana parece nos conduzir à conclusão de que a tese de Schopenhauer sobre a suprema sabedoria flerta com as vãs pretensões práticas da filosofia (denunciadas, por exemplo, por Montaigne) ${ }^{48}$.

Uma concepção de sabedoria que declara que "a mais importante de todas as verdades" [die wichtigste aller $W$ abrheite] é a compreensão de "que não há outro fim a nossa existência senão o de aprender que seria melhor que não existíssemos" 49 dissocia-se, insisto, por inteiro da visão que o sadio entendimento comum tem de sabedoria. Ainda que o sadio entendimento comum continue mirando a sabedoria

\footnotetext{
48 O pensador francês considera uma "sabedoria desumana" aquela que nos torna indiferentes e hostis à cultura do corpo (MONTAIGNE, M. Ensaios, III 13, p. 485). Ora, o asceta recusa os reclames do corpo, pois é por esse meio que nega a vontade de viver. Na tradução de Rosemary Costhek Abílio dos Ensaios consta "sapiência desumana” (p. 485). Em francês, sagesse inhumaine. Quando ao que foi dito acima sobre Schopenhauer, é preciso fazer justiça à sua compreensão de que a filosofia moral não tem finalidades exortativas. As vãs pretensões práticas da filosofia a que me refiro acima devem ser entendias - num sentido genérico - como as pretensões que a filosofia alimenta de oferecer explicações sobre o sentido da vida. Sobre compreensão de Schopenhauer a respeito da filosofia moral, ver referência na nota 25.

49 SCHOPENHAUER, A. MVR II, p. 722. Também se lê no mesmo Suplemento (48): "A existência é certamente para ser vista como um erro, cuja correção é a redenção" (MVR II, p. 722). E nos Parerga: "O valor da vida consiste justamente em ensiná-lo [o homem] a não a querer” (PP II, \172, p. 184). É um erro pensar que existimos para sermos felizes. Mais rigorosamente, trata-se de um erro inato (angeborenen Irrthum). "Há apenas um erro inato, o de que existimos para sermos felizes. Ele é inato em nós, porque coincide com a nossa existência mesma” (MVR II, p. 755). "Ora, quem, por um ou outro caminho, saiu daquele erro a priori que nos é inerente, daquele (Primeiro passo em falso, ou seja, erro originário) da nossa existência, logo verá tudo sob uma luz diferente e agora encontrará o mundo em harmonia, senão com os seus desejos, ao menos com a sua intelecção. Os infortúnios de todo tipo e intensidade, embora lhe doam, não mais o surpreenderão; pois compreendeu claramente que dor e aflição trabalham precisamente em vista do verdadeiro fim da vida, a renúncia da vontade" (MVR II, p. 756-757). O pensamento mais pessimista de Schopenhauer, segundo Janaway, é que apenas a negação da vontade "poderia dar um sentido positivo à nossa existência e ao mundo inteiro" (JANAWAY, J. Schopenhaner's pessimism. p. 341).
} 
como um modo ideal de vida, penso que ele não a mira vislumbrando algum modelo existencial que represente uma evasão da dimensão terrena da vida.

Uma apreciação do valor da vida humana de antemão comprometida com um extremo da escala de valoração da existência afigura-se pouco profícua. A irresignação com padrões terrenos, vale dizer, comuns do existir humano, que sempre implicam afirmação da vontade, e não a sua negação, envolve uma decisão prévia acerca do que poderia ser um modo autenticamente sábio de conduzir a vida. Ora, na minha opinião, a sabedoria envolve a acolhida sem lamentos das servidões próprias da condição humana, assim como um desfrutar sem arrependimentos de seus benefícios. Desse modo, tanto o hedonismo intemperante como uma mutilação ascética de nossa natureza sensível deveriam ser afastados do conceito de sabedoria.

A sabedoria, entendida tanto como (i) o conhecimento das coisas julgadas importantes para a condução da vida como (ii) o modo de viver que reflete esse conhecimento $^{50}$ não implica o pessimismo que Schopenhauer professa. Muitas vezes se tem a impressão de que uma avaliação negativa da vida tal como a professada por Schopenhauer tem como base o questionável pressuposto de que o mundo deveria ser diferente. Mas por que ele deveria ser diferente? Deveria ser diferente para atender aos nossos desejos? É por causa da existência do sofrimento e do tédio que desejaríamos um mundo diferente? Será que não estamos sendo vítimas aqui do que Berkeley (segundo Blackburn) chamou de "vício da abstração" 51 ? Tal vício ocorreria quando "a rede subtil e elegante" de nossas ideias abstratas acaba nos levando a miseráveis perplexidades e enredamentos. Sobre isso vele a pena citar Blackburn:

É mais fácil lamentar a natureza irrisória do desejo e as suas inconsistências se não nos centrarmos em nada, mantendo a discussão em termos abstratos. Desse modo, parece desolador se a satisfação do desejo é efémera e o próprio desejo é instável e susceptível de dar origem apenas a mais insatisfação. Mas será que isto é de lamentar? Pensando em termos concretos, supõe que nos apetece um bom jantar e que ele nos deu prazer. Deverá envenenar o prazer que tivemos a reflexão de que o prazer é efémero (o prazer deste jantar não subsistirá para sempre), de que o desejo de um bom jantar não perdura (mais tarde não sentiremos fome) ou é apenas temporariamente satisfeito (iremos querer jantar amanhã outra vez)? A verdade é que a vida não se tornaria melhor se quiséssemos sempre um jantar, ou se, tendo jantado, não quiséssemos mais nenhum jantar, ou se aquele jantar bastasse para toda a vida. Nenhuma destas coisas parece remotamente desejável; logo, porquê lamentarmo-nos se as coisas não são assim ${ }^{52}$ ?

Schopenhauer considera que "toda vida é sofrimento" [alles Leben Leiden ist ${ }^{53}$. A afirmação poderia ser adequadamente justificada se a entendêssemos como uma

\footnotetext{
50 Ver especificação semântica, consignada no início do artigo, em que falo dos componentes epistêmico e prático da sabedoria.

${ }^{51}$ Uso a expressão "vício da abstração", atribuída a George Berkeley, a partir da leitura de: BLACKBURN, S. Desejo e sentido da vida.

52 BLACKBURN, S. Desejo e sentido da vida, p. 2. Uma crítica diferente, mas convergente no ponto que assinalei, também pode ser encontrada no texto de um estudioso de Schopenhauer. Refiro-me a TANNER, M. Schopenhauer, pp. 25-26.

53 SCHOPENHAUER, A. MVR I, $\int 56$, p. 400.
} 
tese sobre o sofrimento presente em toda vida. Isso pareceria uma descrição plenamente aceitável da existência humana ${ }^{54}$. Agora, se entendermos que a declaração pretende descrever o fundo essencial da vida, então o relato afigura-se parcial. É possível afirmar que nossa existência se apresenta em vários momentos grandiosa. Mais do que isso, é possível afirmar que há vidas prósperas, plenas, realizadas (quando Schopenhauer aproxima-se dessa admissão, ele a abandona como ilusória) ${ }^{55}$. Certamente, toda vida é constituída por sofrimento, mas a afirmar que sofrimento pode definir nossa existência, eis aí uma tese que me parece exagerada e parcial ${ }^{56}$.

Tendo a pensar que a visão condenatória da vida professada por Schopenhauer assemelha-se mais a um olhar subjetivo sobre o mundo do que ao desdobramento de um argumento filosófico consistente ${ }^{57}$. Mesmo que o argumento seja inicialmente sedutor e forneça alguns ingredientes de consistência, essa não parece ser uma verdade necessária ou conceitual.

Algumas vezes, Schopenhauer dá a impressão de que o fato de sermos mortais seria algo como uma condenação, ou confirmação de seu pessimismo. De acordo com Schopenhauer, o fato de que ao fim de nossa existência sobrevenha a morte mostraria que ela é um negócio que não cobre os custos do investimento. Quer dizer que se fossemos eternos o problema da suposta futilidade da existência seria dissolvido? Se fossemos eternos, a vida cobriria os custos do investimento? Aparentemente, Schopenhauer tem uma reposta para essa indagação. Não bastaria a imortalidade, seria preciso também inexistência de sofrimentos em gruas elevados (embora isso não fique muito claro). Ele diz: "sofrimento algum e morte alguma, ou pelo menos nenhuma coisa aterradora, deveriam existir para mim. Só assim a vida cobriria os custos do investimento" "58. Isso é deveras exótico, visto que pode simplesmente ser interpretado como um inconformismo com nossa finitude (como assinalei acima) ${ }^{59}$. A vida cobriria os custos do investimento se não fosse ela a vida humana tal como a conhecemos, marcada pela mortalidade e incontáveis sofrimentos? Notem que não é preciso acusar a compreensão que Schopenhauer tem do sentido e valor da vida humana de inteiramente implausível. Parece-me altamente razoável e de uma sobriedade notável

\footnotetext{
${ }^{54}$ Estou restringindo a tese de Schopenhauer à existência humana, embora ele faça a afirmação num sentido geral. ${ }_{55}$ Quando me refiro à existência de vidas plenas e realizadas estou assumindo que o sentimento que as pessoas têm de que a vida delas é uma vida feliz não pode ser, o próprio sentimento, ilusório.

${ }^{56}$ Sobre a parcialidade da visão de Schopenhauer sobre o valor negativo de nossa existência, vale citar também JANAWAY, C. Schopenhauer's pessimism, p. 33.

57 Minha posição vai ao encontro em linhas gerias da defendida por Simmel. Em uma de suas considerações críticas ao pessimismo de Schopenhauer, Simmel afirma: "conceder maior ou menor valor à existência depende de o ponto mais profundo de cada alma possuir sensibilidade específica para a alegria ou o sofrimento" (SIMMEL, G. Schopenhauer \& Nietzsche, p. 90). Também vale citar Blackburn. "O sorriso do filho significa tudo para a mãe, a carícia significa beatitude para o amante, a mudança de frase significa felicidade para o escritor. O sentido vem da entrega e do prazer, da corrente de pormenores que são importantes para nós. O problema que há com a vida é então o de ela ter demasiado sentido. Todavia, se o estado de espírito é outro, tudo é penoso. Como Hamlet, estamos determinados a esquivar-nos do carnaval humano, não vendo senão a caveira debaixo da pele" (BLACKBURN, S. Desejo e sentido da vida, p. 3).

58 SCHOPENHAUER, A. MVR II, p. 689.

59 "Pois ao fim o tempo proclama a sentença da natureza sobre o valor de todos os seres que nela aparecem, na medida em que os aniquila. E com justiça; pois tudo o que nasce/É digno que pereça. /Por isso o melhor seria não ter nascido. Assim, a velhice e a morte, para as quais toda vida apressa-se necessariamente, são as sentenças condenatórias que saem das próprias mãos da natureza contra a Vontade de vida, pronunciando que essa vontade é uma aspiração sempre destinado ao malogro" (SCHOPENHAUER, A. MVR II, p. 684-685).
} 
reconheceremos as misérias da nossa existência. Mas disso não parece se seguir, por razões meramente conceituais, que seria melhor não existir.

Um aspecto central do pessimismo de Schopenhauer está sujeito a ressalvas. Refiro-me à tese da negatividade do prazer e da felicidade ${ }^{60}$. Essa tese se encontra espalhada em vários momentos de sua obra. Elejo, como abonos, as seguintes citações.

Toda satisfação, ou aquilo que comumente se chama felicidade, é própria e essencialmente apenas NEGATIVA, jamais positiva. Não se trata de um contentamento que chega até nos originariamente; por si mesmo, mas sempre tem de ser a satisfação e um desejo; pois o desejo, isto é, a carência é a condição previa de todo prazer ${ }^{61}$.

A dor e o sofrer, de que faz parte toda a falta, carência e necessidade e mesmo todo o desejo, é o positivo, aquilo que é sentido imediatamente. Ao contrário, a natureza do contentamento, do prazer, da felicidade, consiste só no fato de que uma carência foi suprimida, uma dor aquietada. Estas agem portanto negativamente ${ }^{62}$.

Porém, na sequência imediata dessas linhas (da segunda citação, extraída de Sobre o fundamento da moral), somos contemplados com a seguinte observação: "Já Platão reconheceu isto e excetuou apenas o perfume e as alegrias espirituais"63. Essa exceção que Platão fixa é deveras importante ${ }^{64}$. Com efeito, se Schopenhauer concorda com a advertência que Platão faz, a sua tese da negatividade do prazer resulta numa tese que não valeria para todos os prazeres. Ela perde, pois, a pretensão tipicamente filosófica de ser uma tese de alcance irrestrito. Lamento que Schopenhauer não tenha se detido no sentido dessa exceção, deixando de explorar todo seu alcance. De qualquer forma, temos de reconhecer que se pode oferecer provas textuais de que Schopenhauer admite a existência de prazeres positivos (perfumes e as alegrias espirituais), como atesta a citação acima.

\footnotetext{
${ }^{60}$ Vale consignar uma observação sobre prazer e felicidade. Pode-se afirmar que Schopenhauer entende a felicidade em termos hedonistas ou semi-hedonistas (ver quando falo disso).

${ }^{61}$ SCHOPENHAUER, A. MVR I, $\int 58$, p. 411.

62 SCHOPENHAUER, A. M, pp. 131-132.

${ }^{63}$ SCHOPENHAUER, A. M, p. 132. Schopenhauer oferece o seguinte abono a essa referência a Platão: "Res publica, IX, p. 264 ss. Ed. Bipontini". Trata-se, citando a República de acordo com a forma mais tradicional, de A República, livro 9, 584 a e ss.

${ }^{64}$ A respeito da defesa da positividade do prazer, talvez o filósofo que mais destaque mereceria é Aristóteles. Para os propósitos desse trabalho, valem as seguintes observações. Segundo o estagirita, o "modelo nutritivo" sobre o prazer (uma forma de nomear a natureza negativa do prazer) seria equivocado, visto que baseado em processos fisiológicos de falta e repleção. Segundo Aristóteles o conceito de prazer não diz respeito essencialmente a uma falta não sentida. O prazer resulta da atividade (enérgeia) de uma determinada faculdade (órgãos sensoriais ou o pensamento) que pode funcionar sem entraves (cf. ARISTÓTELES. Ética a Nicômaco, p. 222). No livro VII da Ética a Nicômaco, Aristóteles apresenta a sua definição de prazer: "não é certo dizer que o prazer seja um processo perceptível, mas antes deveríamos chamá-lo atividade do estado natural e, em vez de 'perceptível', 'desimpedida"' (ARISTÓTELES. Ética a Nicômaco, p. 172). Aristóteles discorda, pois, de todos aqueles que consideram o prazer como a satisfação de uma carência. Tendo Aristóteles como referência, Lebrun afirma, com razão, “o prazer não é o contrário da abstinência, mas do aborrecimento, da carranca; não é o que nos arranca soluços e espasmos, mas, mais simplesmente, o que vem do feliz exercício de nossas forças ou de nosso talento - e que, ao mesmo tempo, aumenta a qualidade ou a quantidade de nossa produtividade" (LEBRUN, G. A neutralização do prazer, p. 75).
} 
Podemos encontrar ainda outra passagem estimulante a esse respeito nos Parerga. Ainda que se trate de um contexto em que se faz uma declaração pessimista geral, nota-se o reconhecimento de um prazer que parece não se encaixar na tese da negatividade.

\begin{abstract}
Ora, só apreciamos nossa existência pelo esforço por algo quando a distância e os obstáculos nos fazem pensar que o propósito será satisfatório - ilusão que desaparece quando ele é alcançado; ou então em uma ocupação puramente intelectual, na qual, porém, nos afastamos da vida para considerá-la de fora, como espectadores nos camarotes. Mesmo o prazer sensual consiste em um esforço continuo que cessa tão logo seu objetivo é alcançado. Sempre que não estamos em uma dessas duas situações, mas nos voltamos para a própria existência, somos tomados pela sua futilidade e sua nulidade - e este é o tédio ${ }^{65}$.
\end{abstract}

Eis uma visão interessante sobre prazer intelectual. É possível, porém, diferentemente do que pensa Schopenhauer, compreender o prazer intelectual como algo profundamente mundano assim como os demais prazeres. Com o qualificador mundano quero chamar a atenção para o fato de que não bastaria a alguém simplesmente declarar que, ao gozarmos um prazer intelectual, nos afastamos da vida. Com base em que se pode afirmar isso? Estou fortemente propenso a considerar que os prazeres intelectuais não representam de modo algum uma evasão da vida. Eles não são um tipo de atividade extramundana de mera contemplação do existir, mas constituem também nossa existência, embora não possam ser, por certo, contínuos.

Em acréscimo, cabe assinalar que a passagem acima dos Parerga ( $(146)$ tem a utilidade notável para os propósitos críticos desses parágrafos. Ela revela claramente a admissão de Schopenhauer de uma apreciação positiva da vida. Ou seja, o prazer não estaria num fim, num ponto de chegada, mas no próprio percurso de nosso existir o prazer poderia estar poderia implicado ${ }^{66}$. O elemento complicador aqui está no fato de que Schopenhauer considera isso ilusório, visto que repousa numa mera esperança, insinuada como vã. Mas se for uma ilusão, qual o problema? Como entender uma apreciação (positiva) como ilusória? Se apreciar algo nesse caso envolve um sentimento de que esse algo é bom, isso (esse sentimento) não pode ser ilusório. Naturalmente, se confrontarmos os sentimentos humanos ordinários de satisfação com premissas filosóficas que fixam um sentido objetivo para o que vem a ser a verdadeira satisfação (que resulta impossível), a alegação de Schopenhauer poderia prosperar. Contudo, ela somente consegue prosseguir assumindo uma indevida subtração da vivência subjetiva que as pessoas têm com respeito aos seus anseios e desejos em geral.

Sobre a possível natureza ilusória do prazer e da felicidade, algumas ponderações adicionais serão úteis. Antes de tudo, é importante reforçar (pois isso já

${ }^{65}$ SCHOPENHAUER, A. PP II, \146, p. 142. Isso quase vai ao encontro de Simmel, que pensa estar criticando Schopenhauer. Simmel diz: "Se a ação se realiza conforme essa esperança, normalmente inexiste um sentimento de dor que a acompanhe, embora, enquanto estamos a meio caminho, queiramos o fim, sem tê-lo alcançado ainda. Mesmo assim, a marcha em direção a ele é mais prazerosa que dolorosa. Só será dolorosa no momento em que apareça um obstáculo, em que se perceba que o fim foi atingido ou em que se paralisem as forças" (SIMMEL, G. Schopenhauer \& Nietzsche, p. 78 - grifei).

${ }^{66} \mathrm{O}$ que parcialmente converge com Simmel, que parece não ter se apercebido disso (cf. nota acima). 
pode ser depreendido do que vem sendo dito nas linhas acima) que Schopenhauer assimila a felicidade ao prazer e à satisfação meramente subjetiva ${ }^{67}$. Ora, a felicidade poderia ser entendida como um conceito que qualifica uma vida satisfeita e não apenas um desejo satisfeito. Isso foi o que pensou, em termos aproximativos, Aristóteles e muitos filósofos antigos. Estou feliz se estou feliz com minha vida, mesmo que muitos desejos restem insatisfeitos. Posso ter vários desprazeres e ainda assim me considerar feliz. Por esse ângulo, parece-me altamente atraente e defensável entender que a felicidade "é um bem propriamente humano, que só é concebível em função de recursos propriamente humanos e só tem sentido na escala da vida humana" ${ }^{68}$. Eu acho muito mais fecunda a seguinte visão de felicidade:

O traço mais característico da felicidade é o sentimento de satisfação experimentado em relação à vida inteira e o desejo de que essa vida prossiga do mesmo modo. Tal sentimento de satisfação deve ser relacionado com os desejos e projetos que uma pessoa alimenta em relação à sua vida ${ }^{69}$.

Se a vida humana é o quadro de referência do conceito de felicidade, então não há por que aceitar a visão de Schopenhauer, muitas vezes por ele sustentada e aqui autenticada com a passagem do $\int 38$ de $O$ mundo, segundo a qual o que contaria para a felicidade ou infelicidade seriam os desejos particularmente considerados e não a vida como um todo. É verdade que Schopenhauer também faz uma avaliação negativa da vida considerada globalmente, mas, quando isso ocorre, ele argumenta de modo a repelir uma ponderação sobre estar satisfeito com a vida (como propõe CantoSperber), seja considerando isso no fundo ilusório, seja - o que me parece mais frequente - enfatizando as parcelas infelizes do nosso existir e não apreciação pelo sujeito de sua vida em geral.

Antes de colocar o ponto final nesse texto, registro que as linhas críticas acima representam, por ora, apenas um esboço para uma futura e mais intrépida e desenvolvida crítica à noção schopenhaueriana de sabedoria. O objetivo do artigo foi sobretudo mostrar que a noção forte e rigorosa de sabedoria em Schopenhauer está ligada ao seu pessimismo e é enunciada com limpidez nos Aforismos (livro que ironicamente defende outra visão sobre sabedoria). A suprema sabedoria é essencialmente ascética e pode ser alvejada se mirarmos o pessimismo de Schopenhauer e tentarmos (como é praxe do trabalho filosófico) avalia-lo criticamente. Caso a crítica obtenha algum êxito enfraquecendo o pessimismo de Schopenhauer, a sua noção de suprema sabedoria também é por consequência atingida. Com efeito, a sabedoria implica um componente epistêmico ou teórico e ele, em Schopenhauer, é constituído por seu pessimismo metafísico. Talvez se pudesse afirmar, sob uma tímida e batida inspiração do filósofo de Königsberg, que uma sabedoria meramente teórica é vazia e uma sabedoria apenas prática é cega. Se isso

\footnotetext{
${ }^{67} \mathrm{O}$ que nos autorizaria a dizer que Schopenhauer tem uma visão hedonista ou, no mínimo, semi-hedonista acerca do prazer. Sobre o hedonismo na tese Schopenhaueriana da negatividade do prazer, ver: JANAWAY, C. Schopenhauer's pessimism, p. 332-334.

${ }^{68}$ CANTO-SPERBER, M. Felicidade, p. 613

${ }^{69}$ Ibidem.
} 
proceder, atingida a dimensão teórica da sabedoria suprema, restaria ao pessimismo vivencial subsistir sob severas deficiências visuais.

\section{Referências bibliográficas}

ARISTÓTELES. Ética a Nicômaco. Trad. Leonel Vallandro e Gerd Bornheim. São Paulo: Abril Cultural, 1984.

BLACKBURN, S. Desejo e sentido da vida. Tradução de Faustino Vaz. Crítica. 2005. https://criticanarede.com/eti desejosentido.html < acesso em outubro de 2017>.

CANTO-SPERBER, M. Felicidade. In: Dicionário de ética e filosofia moral - $2^{\mathrm{a}}$ ed. Unisinos: São Leopoldo. 2011, p. 612-623.

GARDINER, P. Schopenhauer. Bristol: Thoemmes Press, 1997.

JANAWAY, C. Schopenhauer's pessimism. In: JANAWAY, Christopher (Org.). Cambridge Companion to Schopenhauer. Cambridge: Cambridge University Press, 1999, p. 318-343.

LEBRUN, G. A neutralização do prazer. In: NOVAES, Adauto (Org.). O Desejo. São Paulo: Cia das Letras; Rio de Janeiro: Funarte, pp. 67-89, 1990.

LEFRANC, J. Compreender Schopenhauer. Trad. Ephraim Ferreira Alves. Petrópolis: Vozes, 2005.

MONTAIGNE, M. Ensaios. Livro III. Trad. Rosemary Costhek Abílio. São Paulo: Martins Fontes, 2001.

PAVÃO, A. Kant e Schopenhauer sobre a natureza da filosofia moral. Dissertatio, Pelotas, v. 30, pp. 135-148, 2009.

PLATÃO. A República. $7^{\mathrm{a}}$. ed. Trad. Maria Helena da Rocha Pereira. Lisboa: Fundação Calouste Gulbenkian, 1993.

RYAN, S. Wisdom. In: Stanford Encyclopedia of Philosophy. 2013. http://plato.stanford.edu/entries/wisdom/. Acesso em 29.06.2016.

SCHIFFER, F. Filosofia sentimental. Trad. Nícia Adan Bonatti. Rio de Janeiro: Difel, 2012. SCHOPENHAUER, A. Die Welt als Wille und Vorstellung. Erster Band. Werke in zehn Bänden. Band II. Zürich: Diogenes Verlag, 1977.

SCHOPENHAUER, A. O mundo como vontade e como representação. Tomo I. Trad. Jair Barboza. São Paulo: Unesp, 2005.

SCHOPENHAUER, A. O mundo como vontade e como representação. Tomo II: Suplementos aos quatro livros do primeiro tomo. Trad. Jair Barboza. São Paulo: Unesp, 2015.

SCHOPENHAUER, A. Parerga e Paralipomena (cap. V, VIII, XII, XIV). Trad. Wolfang Leo Maar. São Paulo: Nova Cultural, 1988 (Os Pensadores).

SCHOPENHAUER, A. Parerga und Paralipomena: kleine philosophische Schriften. Zweiter Band. Diogenes Verlag AG: Zürich, 1977.

SCHOPENHAUER, A. Parerga y Paralipómena II. Trad. Pilar López de Santa María. Madrid: Trotta, 2009. 
SCHOPENHAUER, A. Sobre a ética. Trad. Flamarion C. Ramos. São Paulo: Hedra, 2012. SCHOPENHAUER, A. Sobre a filosofia e seu método. Trad. Flamarion C. Ramos. São Paulo: Hedra, 2010.

SCHOPENHAUER, A. Sobre o fundamento da moral. Trad. Maria Lúcia Cacciola. São Paulo: Martins Fontes, 1995.

SCHOPENHAUER, A. Über die Grundlage der Moral. Kleinere Schriften. Sämtliche Werke, Band III: Bearbeitet und Heraugegebt von Wolfgang Frhr. Von Löhnheysen. Frankfurt am Main: Suhrkamp, 1998, p. 629-815.

SCHOPENHAUER, A. A arte de ser feliæ: exposta em 50 máximas. Trad. Marion Fleischer, Eduardo Brandão, Karina Janini. São Paulo: Martins Fontes, 2001.

SCHOPENHAUER, A. Aforismos para a sabedoria de vida. Trad. Jair Barboza. São Paulo: Martins Fontes, 2006.

SIMMEL, G. Schopenhauer \& Nietzsche. Trad. Cesar Benjamin. Rio de Janeiro: Contraponto, 2011.

TANNER, M. Schopenhauer: metafísica e arte. Trad. Jair Barboza. São Paulo: UNESP, 2001.

Recebido: 23/04/18

Received: $04 / 23 / 18$

Aprovado: $30 / 05 / 18$

Approved: 05/30/18 